\title{
The effect of postoperative malperfusion after surgical treatment of type A acute aortic dissection on early and mid-term survival
}

\author{
Paolo Nardi', Carlo Olevano², Carlo Bassano', Emanuele Bovio', Lorenzo Cecchetti ${ }^{1}$, Stefano Forlani², Giovanni \\ Ruvolo'
}

${ }^{\prime}$ Department of Cardiac Surgery, Tor Vergata University Policlinic, 00133 Rome, Italy.

${ }^{2}$ Department of Cardiothoracic Surgery, Northern General Hospital, Sheffield S5 7AU, UK.

Correspondence to: Dr. Paolo Nardi, Cardiac Surgery Unit, Tor Vergata University Policlinic, Viale Oxford 81, 00133 Rome, Italy. E-mail: pa.nardi4@libero.it

How to cite this article: Nardi P, Olevano C, Bassano C, Bovio E, Cecchetti L, Forlani S, Ruvolo G. The effect of postoperative malperfusion after surgical treatment of type A acute aortic dissection on early and mid-term survival. Vessel Plus 2017;1:77-83.

\section{Article history:}

Received: 06-03-2017

Accepted: 06-04-2017

Published: 27-06-2017

Key words:

Acute type aortic dissection, aortic surgery, malperfusion, survival

\begin{abstract}
Aim: To evaluate whether postoperative malperfusion (PM) affected in-hospital and longterm survival in acute type A aortic dissection (AAAD) surgical patients and to identify risk factors for PM. Methods: Patients who underwent AAAD surgery at a single institution between January 2005 and March 2015 were retrospectively analyzed. Results: Twohundred fourteen patients with complete data were identified. At presentation, 119 patients (55.6\%) showed preoperative malperfusions: 68 (31.8\%) were cerebral, $38(17.7 \%)$ were renal, and $13(6.1 \%)$ were mesenteric. PM was found in 55 patients $(25.7 \%)$. In-hospital mortality was $47.3 \%$ (26/55) vs. $22.6 \%(36 / 159)$ in PM and non-PM patients, respectively $(P<0.0001)$. Independent predictors for in-hospital mortality included being 75 years or older [odds ratio (OR): 1.1, 95\% confidence interval (CI): 1.03-1.13, $P<0.001]$ and having renal PM (OR: 53.5 , $95 \%$ CI: 3.97-721.3, $P<0.01)$. Five-year survival was $78.6 \pm 7.8 \%$ vs. $93.9 \pm 3.4 \%$ in $\mathrm{PM}$ and non-PM patients, respectively $(P<0.001)$. Independent predictors for long-term survival were being at least 75 years old (OR: 3.7, 95\% CI: 0.9-14.0, $P=0.05$ ) and having renal PM (OR: 28.6, 95\% CI: $1.8-462.0, P=0.01)$. PM and intimal tears distal to the ascending aorta or the proximal aortic arch were also risk factors. Conclusion: PM, especially with renal involvement, is associated with in-hospital mortality and reduced long-term survival. AAAD surgeries reduced preoperative malperfusions. Sites of cannulation and interventions requiring circulatory arrest during cardiopulmonary bypass were not predictors of PM.
\end{abstract}

\section{INTRODUCTION}

Acute type A aortic dissection (AAAD) is a lifethreatening condition and one of the most challenging diseases faced by cardiothoracic surgeons. Despite preventative measures including early surgical referrals for patients, preoperative care and improved surgical techniques, in-hospital mortality following surgery remains high, ranging from $10 \%$ to $30 \% .^{[1,2]}$

Malperfusion of systemic organs is a complication of aortic dissection caused by branch-vessel 
involvement. Occurrences can result in dangerous end-organ ischemic dysfunctions, especially when involving the brain. Clinical diagnoses are critical to the development of effective treatment strategies. Proper diagnoses also have important influence on immediate and long-term outcomes of treatment. ${ }^{[3-5]}$

Malperfusion following either type A or type B acute aortic dissection, is a fairly common complication. It can involve several arterial regions including the cerebral, renal, or mesenteric segments, as well as the upper or lower limbs. In the Stanford Classification Type A Dissection (De Bakey Classification Types I and II) surgical treatment can prevent this complication. In the event of malperfusion, distal aortic percutaneous fenestration can allow blood flow to return to the true lumen. Alternatively, when the distal aortic true lumen is completely obstructed, an endovascular stent can be inserted to recanalize the lower arteries (i.e. the celiac trunk, renal, superior mesenteric and iliac arteries). The International Registry of Acute Aortic Dissection (IRAD) does not include malperfusion as an independent predictor of mortality. Nonetheless, several studies have supported the relevance of this complication, given that it increased in-hospital mortality and adversely affected late survival. ${ }^{[6-9]}$

The aim of this study was to evaluate the effect of postoperative malperfusion (PM) on in-hospital mortality and long-term survival in patients undergoing surgery for $A A A D$ in a single, high-volume aortic surgery center.

\section{METHODS}

Between January 2005 and December 2015, 227 patients (mean age $62.5 \pm 12.6$ years) underwent emergent operations for AAAD. The study was approved by the local Institutional Review Board, which waived the need for patient consent. The preoperative patients' characteristics are given in Table 1.

The diagnosis of malperfusion was based on clinical symptoms and/or imaging evidence, i.e. absence of organ perfusion as determined by computed tomography (CT) scan angiography.

Malperfusion was classified as: cerebral if there was presence of a focal or global stroke leading to brain function deterioration that persisted more than $24 \mathrm{~h}$, or a transient ischemic attack; renal if there was an impairment of renal function (e.g. anuria requiring continuous venovenous hemofiltration, or a two-fold increase of creatinine serum level); or mesenteric if there was evidence of tense abdominal or intestinal dysfunction, or increased serum levels of liver and/or pancreatic enzymes. The database queries were completely obtained from 214 patients.

\section{Surgical techniques}

Prior to operative procedures, patients were monitored with Swan-Ganz pulmonary artery catheters, arterial cannulations to ensure continuous arterial blood pressure measurements (i.e. radial or femoral measurements), and corporeal temperature measurements (TC) during surgery (i.e. rectal, esophageal, or tympanic measurements). Additionally, cerebral monitoring was performed with near-infrared spectroscopy (INVOS ${ }^{\circledR}$ System, Somanetics Corp., Troy, MI, USA) and transcranial Doppler measurements of blood flow velocities in the middle and/or anterior cerebral arteries of the Willis circle.

The heart was accessed through a complete median longitudinal sternotomy in all patients. Arterial access for cardiopulmonary bypass was through either the femoral artery $(n=96)$, the right axillary artery $(n=$ $96)$, or direct aortic cannulation $(n=22)$. Aortic repair was performed in conditions of circulatory arrest and moderate hypothermia $\left(25-28{ }^{\circ} \mathrm{C}\right)$ in $124(58 \%)$ patients.

Cerebral perfusion was given in $118(55.1 \%)$ cases. Fifty-three $(24.8 \%)$ patients received unilateral selective antegrade perfusion across the right axillary artery in the right common carotid artery. Sixty-five $(30.4 \%)$ patients received bilateral perfusion using the Kazui technique. ${ }^{[10,11]}$

Table 1: Preoperative characteristics, $n(\%)$

\begin{tabular}{|c|c|c|c|c|}
\hline Variable & $\begin{array}{c}\text { Overall } \\
(n=214)\end{array}$ & $\begin{array}{c}\text { non-PM } \\
(n=159)\end{array}$ & $\begin{array}{c}\text { PM } \\
(n=55)\end{array}$ & $\begin{array}{c}P \\
\text { value }\end{array}$ \\
\hline Age (years), mean \pm SD & $62.5 \pm 12.6$ & $62.3 \pm 13.5$ & $63.2 \pm 10.6$ & NS \\
\hline Male gender & $156(72.9)$ & 114 & 42 & NS \\
\hline \multicolumn{5}{|l|}{ Clinical history } \\
\hline Hypertension & $188(87.9)$ & 138 & 50 & NS \\
\hline Smoke habit & 69 (32.2) & 49 & 20 & NS \\
\hline BMI $\left(\mathrm{kg} / \mathrm{m}^{2}\right)>30$ & $48(22.4)$ & 33 & 15 & NS \\
\hline History of CAD & $15(7.0)$ & 10 & 5 & NS \\
\hline Diabetes on insulin & $11(5.1)$ & 7 & 4 & NS \\
\hline Previous cardiac surgery & $9(4.2)$ & 6 & 3 & NS \\
\hline $\begin{array}{l}\text { Dialisys-dependent } \\
\text { renal failure }\end{array}$ & $4(1.8)$ & 1 & 3 & 0.02 \\
\hline \multicolumn{5}{|l|}{ Malperfusion, $n(\%)$} \\
\hline Overall malperfusion & $119(55.6)$ & & & \\
\hline Brain & $68(31.8)$ & 47 & 21 & NS \\
\hline Kidney & $38(17.7)$ & 26 & 12 & NS \\
\hline Visceral & $13(6.1)$ & 8 & 5 & NS \\
\hline \multicolumn{5}{|c|}{ Entry tear aortic dissection } \\
\hline Ascending aorta & $115(53.7)$ & 91 & 24 & NS \\
\hline Aortic arch & $33(15.4)$ & 23 & 10 & NS \\
\hline Descending aorta & $8(3.7)$ & 3 & 5 & 0.02 \\
\hline Unknown & $58(27.1)$ & 42 & 16 & NS \\
\hline
\end{tabular}

PM: postoperative malperfusion; BMI: body mass index; CAD: coronary artery disease; NS: not significant 
Table 2: Surgical variables

\begin{tabular}{|c|c|c|c|c|}
\hline Variable & Overall $(n=214)$ & non-PM $(n=159)$ & $\mathrm{PM}(n=55)$ & $P$ value \\
\hline \multicolumn{5}{|l|}{ Arterial cannulation, $n(\%)$} \\
\hline Right axillary & $96(44.9)$ & 69 & 27 & NS \\
\hline Right or left femoral & $96(44.9)$ & 72 & 24 & NS \\
\hline Central (into the aorta) & $22(10.2)$ & 18 & 4 & NS \\
\hline \multicolumn{5}{|l|}{ Brain perfusion, $n(\%)$} \\
\hline Monolateral & $53(24.7)$ & 38 & 15 & NS \\
\hline Bilateral & $65(30.4)$ & 48 & 17 & NS \\
\hline Not performed & $96(44.9)$ & 74 & 22 & NS \\
\hline Circulatory arrest, $n(\%)$ & $125(58.4)$ & 90 & 35 & NS \\
\hline Circulatory arrest temperature $\left({ }^{\circ} \mathrm{C}\right)$, mean $\pm \mathrm{SD}$ & $27 \pm 2$ & $26.9 \pm 2.5$ & $27.1 \pm 1.9$ & NS \\
\hline \multicolumn{5}{|l|}{ Surgical times $(\mathrm{min})$, mean $\pm \mathrm{SD}$} \\
\hline CPB & $161 \pm 82$ & $160.9 \pm 87.5$ & $168.8 \pm 67.6$ & NS \\
\hline Aortic cross clamp & $91 \pm 47$ & $92.2 \pm 46.4$ & $95.2 \pm 46.4$ & NS \\
\hline Circulatory arrest & $38 \pm 31$ & $37.6 \pm 32.4$ & $39.5 \pm 30.8$ & NS \\
\hline \multicolumn{5}{|l|}{ Surgical procedures, $n(\%)$} \\
\hline AAR & $72(33.6)$ & 53 & 19 & NS \\
\hline AAR + hemiarch replacement & $50(23.4)$ & 34 & 16 & NS \\
\hline AAR + arch replacement & $38(17.8)$ & 29 & 9 & NS \\
\hline Bentall & $43(20.1)$ & 36 & 7 & NS \\
\hline Bentall + hemiarch replacement & $11(5.1)$ & 7 & 4 & NS \\
\hline
\end{tabular}

PM: postoperative malperfusion; CPB: cardiopulmonary bypass; AAR: ascending aorta replacement; NS: not significant

Three regions of the aorta (ascending, arch and proximal descending) were investigated in each patient to identify sites of intimal tearing; tears were resected whenever possible. Intimal tearing occurred in the ascending aorta in $115(53.7 \%)$ patients, in the arch in $33(15.4 \%)$ patients, and in the descending aorta in $8(3.7 \%)$ patients. In $58(27.1 \%)$ patients no entry tear was found. Seventy-two patients (33.6\%) underwent isolated ascending aortic replacement, $50(23.4 \%)$ had hemiarch resection and $38(17.8 \%)$ had both total arch replacement and ascending aortic replacement. The aortic root was replaced in $43(20.1 \%)$ patients using the modified button Bentall technique. Intraoperative data are given in Table 2.

\section{Data collection}

In-hospital mortality events included both intraoperative and postoperative mortality within 30 days after surgery. Clinical follow-up visits were performed every 12 months in our outpatient control unit; CT-angiography and/or echocardiographic data were collected. For patients living far from this institution who could not participate in regular follow-up visits to the department, clinical status was ascertained by personal interviews with the patients and their cardiologists, including the recording of noninvasive tests.

\section{Statistical analyses}

Statistical analyses were performed using StatView 4.5 programming (SAS Institute Inc., Abacus Concepts, Berkeley, CA, USA). Student's $t$-test for continuous variables and Chi-squared or Fisher's exact tests for categorical variables were used. To detect independent predictors of in-hospital mortality and PM logistic regression analyses were performed. Statistical significance by univariate analyses $(P<$ $0.10)$ were required for entry into the multivariate models. Preoperatively analyzed variables included: age, gender, arterial hypertension, smoking status, body mass index, history of concomitant coronary artery disease, diabetes, chronic kidney disease, previous cardiac surgery, left ventricular dysfunction [e.g. left ventricular ejection fraction $(\mathrm{LVEF})<40 \%$ ], presence of preoperative malperfusion, and the sites of entry tears. Intraoperatively analyzed variables included: cannulation sites, techniques for obtaining brain perfusions, surgical times, whether there was a need for circulatory arrest, and types of operations (i.e. isolated ascending aorta replacement, Bentall procedure, ascending aortic replacement extended to the hemiarch, or total arch replacement). Overall longterm survival (not including operative mortality) was expressed as a mean of the values plus or minus one standard deviation. Survival analyses were computed using the Kaplan-Meier method; Mantel-Cox logrank tests were used to compare survival estimates between subgroups. Cox regression models were used to evaluate the influence of the variables on time to death in the entire cohort. A $P$ value less than 0.05 was considered statistically significant.

\section{RESULTS}

At presentation, 119 (55.6\%) patients exhibited preoperative malperfusion: $68(31.8 \%)$ were cerebral with neurological symptoms, $38(17.7 \%)$ were renal, and $13(6.1 \%)$ were mesenteric. The most relevant 
Table 3: Predictors of in-hospital mortality

\begin{tabular}{lcccc}
\hline \multirow{2}{*}{ Variable } & Univariate & \multicolumn{3}{c}{ Multivariate } \\
\cline { 2 - 5 } & $\boldsymbol{P}$ value & OR & $\mathbf{9 5 \%}$ Cl & $\boldsymbol{P}$ value \\
\hline Age $\geq 75$ years & 0.0078 & 1.1 & $1.0-1.1$ & 0.0004 \\
Renal PM & $<0.0001$ & 53.5 & $4.0-721.3$ & 0.0027 \\
Any preoperative & $<0.0001$ & & & 0.14 \\
malperfusion syndromes & & & & \\
Preoperative cerebral & 0.0345 & & & 0.62 \\
preoperative malperfusion & 0.0131 & & & 0.40 \\
BMI > 30 & 0.0353 & & & 0.15 \\
CABG & 0.0008 & & & 0.12 \\
CPB time & 0.0225 & & & 0.90 \\
Aortic cross clamp time & &
\end{tabular}

PM: postoperative malperfusion; BMI: body mass index; CABG: coronary artery bypass grafting; CPB: cardiopulmonary bypass; OR:odds ratio; $\mathrm{Cl}$ : confidence interval

clinical characteristics of the cohort, stratified according to the presence or absence of PM, were reported in Table 1.

Intraoperative mortality occurred in $14(6.5 \%)$ patients and in-hospital mortality after surgery occurred in 48 $(22.4 \%)$ patients. Using univariate analyses, significant risk factors for in-hospital mortality included: being at least 75 years old, having a body mass index of more than $30 \mathrm{~kg} / \mathrm{m}^{2}$, having preoperative overall or cerebral malperfusion, having longer cardiopulmonary bypass and aortic clamping times, needing concomitant coronary artery bypass grafting (CABG), having renal $\mathrm{PM}$ requiring continuous veno-venous hemofiltration, and have postoperative mechanical ventilation for up to $24 \mathrm{~h}$. The multivariate analyses revealed that being 75 years old or older at the time of surgery $(P<0.001)$ and having renal PM $(P<0.01)$ were independent predictors of in-hospital mortality [Table 3].

Fifty-five $(25.7 \%)$ patients showed clinical symptoms and/or imaging evidence of PM. In 42 cases, only 1 organ system was affected, including: the brain in 13 (6.5\%) patients, the kidneys in $22(10.3 \%)$ patients, and the viscera in $7(3.3 \%)$ patients. In a subgroup of PM patients with just 1 affected organ system, the mortality rate was $40.5 \%$. In 11 patients, PM occurred in 2 organ systems ( 5 in the brain and kidneys, 3 in the brain and viscera, 3 in the kidneys and viscera); the mortality rate in this subgroup was $63.6 \%$. PM involving all 3 organ systems occurred in just 2 cases and both patients died. Overall, the in-hospital mortality rate in patients affected by any PM was $47.3 \%(26 / 55)$ vs. $22.6 \%(36 / 159)$ in patients without PM $(P<0.001)$. Univariate analyses identified that the risk factors for any PM included: having a preoperative LVEF of less than $40 \%(P<0.01)$, having preoperative renal dysfunction $(P<0.05)$ and having an entry tear distal to the ascending aorta or to the proximal aortic arch $(P$ $<0.05$ ). Multivariate analyses determined that having
Table 4: Predictors of postoperative malperfusion syndrome

\begin{tabular}{lcc}
\hline Variable & Univariate & Multivariate \\
\cline { 2 - 3 } & $\boldsymbol{P}$ value & $\boldsymbol{P}$ value \\
\hline Preoperative LVEF $<40 \%$ & 0.007 & 0.04 \\
$\begin{array}{l}\text { Preoperative dialysis } \\
\begin{array}{l}\text { Entry tear distal to the } \\
\text { ascending aorta - proximal } \\
\text { aortic arch }\end{array}\end{array}$ & 0.03 & $\mathrm{NS}$ \\
\hline
\end{tabular}

LVEF: left ventricular ejection fraction; OR: odds ratio; $\mathrm{Cl}$ : confidence interval; NS: not significant

a LVEF value of $40 \%$ or less was the only independent predictor of having a PM $(P<0.05)$ [Table 4].

Preoperative cerebral malperfusion was an independent predictor of cerebral PM [odds ratio (OR): 2.5, 95\% confidence interval $(\mathrm{Cl}): 1.0-6.1, P<0.05]$. Interestingly, a LVEF of less than $40 \%$ was only a found to be a significant risk factor for renal PM when using univariate analysis techniques $(P<0.0001)$. Finally, an entry tear distal to the ascending aorta or to the proximal aortic arch requiring extensive repair and longer surgical time was a risk factor of mesenteric PM $(P<0.05$, using univariate analyses).

\section{Follow-up results}

The mean duration of follow-up was $42.4 \pm 23.7$ months (median 46 months). All patients were followed until the end of the study period. One- and 5-year overall survival rates were $96.0 \pm 1.6 \%$ and $90.8 \pm$ $3.2 \%$, respectively [Figure 1]. Cox regression analyses identified that independent predictors of long-term survival were: being at least 75 years old at the time of surgery (OR: $3.7,95 \% \mathrm{Cl}: 0.9-14.0, P=0.05$ ) and having a renal PM (OR: 28.6, 95\% Cl: 1.8-462.0, $P$ $=0.01$ ) [Table 5]. When the survival probability was dichotomized by age, (with a threshold of 75 years old at the time of the surgery), the 5-year survival rates were $91.6 \pm 3.5 \%$ for patients $<75$ years old and 65.1 $\pm 19.5 \%$ for patients $\geq 75$ years old $(P<0.05)$. The 5 -year survival rate for patients without PM was 93.9 $\pm 3.4 \%$ vs. $78.6 \pm 7.8 \%$ for those affected by PM (Logrank test, $P<0.01$ ).

\section{DISCUSSION}

Despite improvements in medical management and surgical techniques, acute type A aortic dissections still have high mortality and morbidity rates. ${ }^{[1,2]}$ The IRAD revealed that the expected mortality rate for patients undergoing AAAD surgery ranges from $20 \%$ to $30 \%{ }^{\left[{ }^{[9]}\right.}$ Our cardiac surgery division has extensive experience in the treatment of acute aortic dissection; we observed an in-hospital mortality rate of $29 \%$. Several studies 
Table 5: Predictors of late mortality

\begin{tabular}{|c|c|c|c|c|}
\hline \multirow{2}{*}{ Variable } & \multirow{2}{*}{$\frac{\text { Univariate }}{\boldsymbol{P} \text { value }}$} & \multicolumn{3}{|c|}{ Multivariate } \\
\hline & & OR & $95 \% \mathrm{Cl}$ & $P$ value \\
\hline Age $\geq 75$ years & 0.03 & 3.7 & $0.9-14.0$ & 0.05 \\
\hline Renal PM & $<0.0001$ & 28.9 & $1.8-462.0$ & 0.017 \\
\hline Cerebral PM & 0.001 & & & NS \\
\hline Visceral PM & 0.09 & & & NS \\
\hline Any PM & 0.001 & & & NS \\
\hline $\begin{array}{l}\text { Entry tear (distal vs. } \\
\text { proximal) of the dissection }\end{array}$ & 0.02 & & & NS \\
\hline
\end{tabular}

PM: postoperative malperfusion; OR:odds ratio; $\mathrm{Cl}$ : confidence interval; NS: not significant

show that both patient characteristics and multi-organ involvement (i.e. affecting the brain, kidney, and mesenteric organs) play a key role in immediate and post-procedural outcomes. For example, Caus et al. ${ }^{[12]}$ showed that being at least 70 years old at the time of operation was an independent predictor of worsened outcomes for AAAD treated patients; these authors reported a 5 -year survival rate of $30 \%$. These data are similar to the clinical experience reported here, in which patients who were at least 75 years old had lower actuarial survival rates than patients under 75 years of age $(65.1 \pm 19.5 \%$ vs. $91.6 \pm 3.5 \%)$.

Malperfusion of organ systems remains a severe condition that is frequently associated with adverse outcomes in AAAD patients undergoing surgical procedures. Data from the German Registry for AAAD suggested that the number of organs involved in the malperfusion was associated with immediate outcomes of surgery. In fact, outcomes were substantially worsened in the presence of any type of malperfusion syndrome, which was exacerbated with increased numbers of affected organs. A $12.6 \%$ early mortality rate was observed in the absence of malperfusion versus $43.4 \%$ mortality in patients with three organ systems affected by malperfusion. ${ }^{[13]}$ Here, preoperative clinical symptoms and/or imaging evidence of malperfusion occurred in 119 patients. After surgery, 55 (25.7\%) patients had malperfusion syndrome. In-hospital mortality was significantly higher $(47.3 \%, 26$ patients) in this group compared to patients without PM $(22.6 \%, 36$ patients) $(P<0.0001)$. Despite the small sample size per group, a strong association between the number of malperfused organs and early mortality was observed. In fact, when 2 organs were affected operative mortality elevated to greater than $60 \%$.

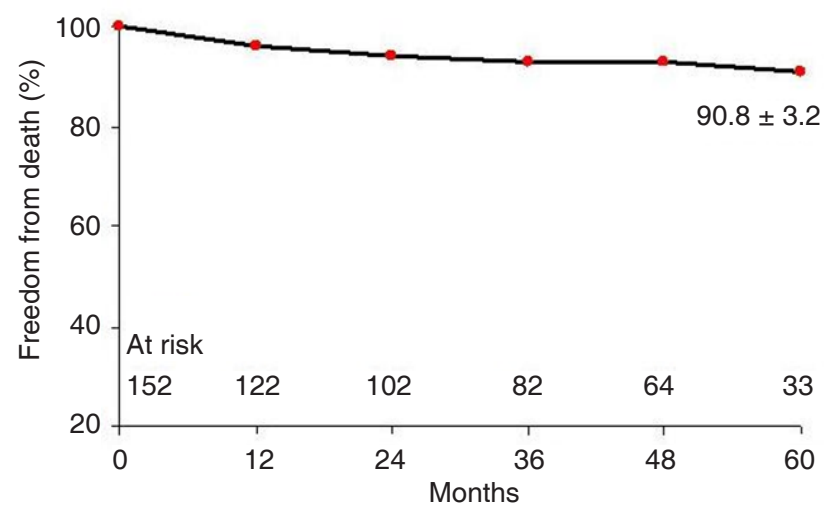

Figure 1: Overall late survival

Furthermore, these data show that PM-affected patients had lower survival probabilities when compared to those who did not develop this postoperative complication $(78.6 \pm 7.8 \%$ vs. $93.9 \pm 3.4 \%)$. Correlations between the preoperative presence of malperfusion and mortality have been previously described. ${ }^{[14,15]}$ Pacini et al. ${ }^{[14]}$ found that patients presenting with any malperfusion syndrome had a mortality rate of $43.7 \%$, compared to $15 \%$ in patients without malperfusion $(P=0.001)$; strikingly, mortality rates were $34.7 \%, 61.9 \%$ and $85.7 \%$ with involvement of 1,2 , or more than 2 organ malperfusions, respectively. Mesenteric malperfusion was identified as an independent predictor of operative mortality. Similarly, Geirsson et al. ${ }^{[15]}$ reported a $30.5 \%$ operative mortality in the presence of any malperfusion syndrome; in this study cerebral malperfusion was detected as a risk factor for in-hospital mortality $(P<$ $0.001)$ and reduced long-term survival $(P=0.0002)$.

In the present study, the most important independent risk factor of early and 5-year mortality was presence of a renal PM requiring continuous veno-venous hemofiltration. Previously, we identified in 100 consecutive patients receiving AAAD operations from 1995 to 2006, that renal failure, either chronic (OR: 0.3, $P=0.04$ ) or developed acutely in the postoperative period (OR: 8.9, $P=0.001$ ), was a predictor of operative mortality. However, renal failure was not a predictor of reduced 5-year survival. ${ }^{[8]}$ In the same group of patients, preoperative LVEF values of less than $50 \%$ were also predictors of reduced survival $(P=0.02)$.

Another important issue is the surgical timing of aortic repairs. Previous authors have suggested delaying acute aortic dissection surgeries when patients experience preoperative malperfusion, particularly in the mesentery. This delayed treatment strategy involved early endovascular treatment with a complete or partial resolution of organ ischemia, followed by timely aortic surgeries. ${ }^{[16,17]}$ While this management approach may be beneficial in a specific subpopulation, 
patient $A A A D$ survival outcomes have been shown to relate closely to the length of time between diagnoses and surgeries. ${ }^{[18,19]}$ Given the high mortality of patients with mesenteric malperfusion (40-100\%), initial management with an interventional procedure treating the condition should be considered. ${ }^{[20,21]}$ In fact, previous data suggested that mesenteric malperfusion was associated with the highest mortality rates when compared to malperfusions occurring in any other organ systems. The surgical strategy presented here, consisting of immediate aortic dissection treatment, showed that incidence of preoperative malperfusion was reduced roughly in half; from $56 \%$ preoperatively to $25 \%$ in the immediate postoperative period.

Univariate analyses of preoperative variables determined that three risk factors predicted the occurrence of a PM in any organ system. These risk factors were: having a LVEF less than $40 \%$, having renal impairment that required continuous hemofiltration, and having an entry tear distal to the ascending aorta or the proximal aortic arch. However, the only variable that maintained significance in the multivariate model was having a preoperative LVEF of less than $40 \%$. Reduced ejection fraction likely associated with concomitant ischemic coronary disease, which could have increased the risk of a postoperative low cardiac function and subsequent PM. Juxtaposition of intimal tears distal to the ascending aorta or the proximal arch were non-significant factors in the multivariate analyses. However, these factors contributed risk to progression of aortic disease and PM. Patients with a primary entry tear in the descending aorta were at the highest risk of PM. These patients probably required additional extensive repairs compared to patients with primary entry tears in the ascending aorta. Some of these high-risk patients may benefit from a "frozen elephant trunk" procedure to address the entire pathology. ${ }^{[22]}$

Analysis of preoperative variables contributing risk for each type of PM revealed that only one variable independently predicted cerebral PM: preoperative cerebral malperfusion (OR: 2.5, 95\% Cl: 1.0-6.1, $P<$ 0.05). Shortening the length of time between onset of cerebral symptoms and dissected aortic surgery was critical for improved outcomes in this subset of patients. Estrera et al. ${ }^{[23]}$ reported improved outcomes in AAAD patients who underwent cardiac surgeries within $10 \mathrm{~h}$ of neurological symptom onsets.

With regard to arterial cannulation sites, some authors have suggested that cannulation of the axillary artery will ensure better brain protection during surgery. However, the experience reported here did not confirm this evidence. Nonetheless, many surgeons still limit the extent of surgery to the ascending aorta, even though limited repair has a higher probability of reintervention on the remaining aortic segments at a later date. The primary aim of performing AAAD is as an emergent, life-saving procedure. If a center is only able to perform a limited repair technique, but still saves the life of the patient, then the primary intention of the procedure has been achieved. ${ }^{[24,25]}$

In this study, no independent predictors of renal and mesenteric PM were identified. However, using univariate analyses, having a LVEF value less than $40 \%$ was statistically relevant $(P<0.0001)$. Additionally, having entry tears distal to ascending aortic segments that required extensive repairs and longer surgical times was also recognized as a significant risk factor $(P<0.05)$.

This study had several limitations. First, it was a retrospective analysis of an experience at a single institution. Second, preoperative treatments to address organ malperfusions were not performed. Third, the possible effects of revascularization strategies for the treatment of PM were not explored. Revascularization techniques may improve long-term outcomes.

In conclusion, PM is a severe condition that is frequently associated with adverse immediate and long-term outcomes in surgical AAAD patients. At this institution, the incidence of PM after AAAD surgery was noteworthy, occurring in roughly $10 \%$ of patients. AAAD surgical procedures effectively reduced preoperative malperfusions in about half of cases. In fact, repairs to the ascending aorta and proximal arch, as well as removal of primary tears, significantly increased the true lumen flow and allowed treatment of a majority of malperfusion syndromes, including those in the cerebral, mesenteric, and renal systems. Postoperative malperfusion, especially involving the kidneys, was associated with high in-hospital mortality and reduced long-term survival. There was no evidence that the types of surgical techniques undertaken, the sites of cannulation, or the use of more complex interventions (requiring circulatory arrest during cardiopulmonary bypass) were risk factors contributing to PM.

\section{Authors' contributions}

Study design: P. Nardi, C. Olevano, C. Bassano, E. Bovio, G. Ruvolo

Development of methodology: P. Nardi, C. Bassano Collection of data: C. Olevano, E. Bovio, L. Cecchetti Analysis and/or interpretation of data: P. Nardi, C. Olevano, C. Bassano, E. Bovio

Writing (not revising) all or sections of the manuscript: 
P. Nardi, C. Olevano, E. Bovio, S. Forlani

Manuscript review: P. Nardi, E. Bovio, L. Cecchetti

Supervision: G. Ruvolo

\section{Financial support and sponsorship}

None.

\section{Conflicts of interest}

There are no conflicts of interest.

\section{Patient consent}

The local Institutional Review Board waived the need for patient consent.

\section{Ethics approval}

The study was approved by the local Institutional Review Board.

\section{REFERENCES}

1. Colli A, Carrozzini M, Galuppo M, Comisso M, Toto F, Gregori D, Gerosa G. Analysis of early and long-term outcomes of acute type A aortic dissection according to the new international aortic arch surgery study group recommendations. Heart Vessels 2016;31:1616-24.

2. Berretta P, Patel HJ, Gleason TG, Sundt TM, Myrmel T, Desai N, Korach A, Panza A, Bavaria J, Khoynezhad A, Woznicki E, Montgomery D, Isselbacher EM, Di Bartolomeo R, Fattori R, Nienaber CA, Eagle KA, Trimarchi S, Di Eusanio M. IRAD experience on surgical type A acute dissection patients: results and predictors of mortality. Ann Cardiothorac Surg 2016;5:346-51.

3. Orihashi K. Malperfusion in acute type A aortic dissection: unsolved problem. Ann Thorac Surg 2013;95:1570-6.

4. Fabre O, Guesnier L, Renaut C, Gautier L, Geronimi H, Jasaitis L, Strauch K. Current treatment of acute type A aortic dissection. Surgical treatment and treatment of malperfusion syndrome. Ann Cardiol Angeiol (Paris) 2005;54:332-8. (in French)

5. Immer FF, Grobéty V, Lauten A, Carrel TP. Does malperfusion syndrome affect early and mid-term outcome in patients suffering from acute type A aortic dissection? Interact Cardiovasc Thorac Surg 2006;5:187-90.

6. Zhang J, Jiang Y, Gao C, Feng J, Wang A. Risk factors for hospital death in patients with acute aortic dissection. Heart Lung Circ 2015;24:348-53.

7. Appoo JJ, Pozeg Z. Strategies in the surgical treatment of type A aortic arch dissection. Ann Cardiothorac Surg 2013;2:205-11.

8. Nardi P, Scafuri A, Pellegrino A, Bassano C, Zeitani J, Bertoldo F, Penta de Peppo A, Chiariello L. Surgery for type A aortic dissection: long-term results and risk factor analysis. G Ital Cardiol (Rome) 2007;8:580-5. (in Italian)

9. Rampoldi V, Trimarchi S, Eagle KA, Nienaber CA, Oh JK, Bossone E, Myrmel T, Sangiorgi GM, De Vincentiis C, Cooper JV, Fang J, Smith D, Tsai T, Raghupathy A, Fattori R, Sechtem U, Deeb MG, Sundt TM 3rd, Isselbacher EM; International Registry of Acute Aortic Dissection (IRAD) Investigators. Simple risk models to predict surgical mortality in acute type A aortic dissection: the International Registry of Acute Aortic Dissection score. Ann Thorac Surg 2007;83:55-61.
10. Bassano C, Mve Mvondo C, Bovio E, Chiariello L. Bilateral cerebral perfusion via right axillary artery cannulation alone in aortic arch surgery. Thorac Cardiovasc Surg 2013;61:584-6.

11. Kazui T, Kimura N, Yamada O, Komatsu S. Surgical outcome of aortic arch aneurysms using selective cerebral perfusion. Ann Thorac Surg 1994;57:904-11.

12. Caus T, Frapier JM, Giorgi R, Aymard T, Riberi A, Albat B, Chaptal PA, Mesana T. Clinical outcome after repair of acute type A aortic dissection in patient over 70 years-old. Eur J Cardiothorac Surg 2002;22:211-7.

13. Czerny M, Schoenhoff F, Etz C, Englberger L, Khaladj N, Zierer A, Weigang E, Hoffmann I, Blettner M, Carrel TP. The impact of preoperative malperfusion on outcome in acute type A aortic dissection: results from the GERAADA registry. $J$ Am Coll Cadiol 2015;65:262835.

14. Pacini D, Leone A, Belotti LM, Fortuna D, Gabbieri D, Zussa C, Contini A, Di Bartolomeo R; RERIC (Emilia Romagna Cardiac Surgery Registry) Investigators. Acute type A aortic dissection: significance of multiorgan malperfusion. Eur J Cardiothorac Surg 2013;43:820-6

15. Geirsson A, Szeto WY, Pochettino A, McGarvey ML, Keane MG Woo YJ, Augoustides JG, Bavaria JE. Significance of malperfusion syndromes prior to contemporary surgical repair for acute type A dissection: outcomes and need for additional revascularizations. Eur J Cardiothorac Surg 2007;32:255-62.

16. Perera N, Galvin SD, Seevanayagam S, Matalanis G. Optimal management of acute type A aortic dissection with mesenteric malperfusion. Interact Cardiovasc Thorac Surg 2014;19:290-4.

17. Yamashiro $\mathrm{S}$, Arakaki $\mathrm{R}$, Kise $\mathrm{Y}$, Inafuku $\mathrm{H}$, Kuniyoshi $\mathrm{Y}$. Management of visceral malperfusion complicated with acute type A aortic dissection. Interact Cardiovasc Thorac Surg 2015;21:346-51.

18. Deeb GM, Williams DM, Bolling SF, Quint LE, Monaghan H, Sievers J, Karavite D, Shea M. Surgical delay for acute type A dissection with malperfusion. Ann Thorac Surg 1997;64:1669-75.

19. Tsagakis K, Pizanis N, Kamler M, Konorza T, Zoepf T, Erbel R, Jakob H. ICU controlled delay for acute type A aortic dissection repair after intervention for total visceral malpefusion: a way out of a dilemma? Thorac Cardiovasc Surg 2008;56:298-300.

20. Slonim SM, Miller DC, Mitchell RS, Semba CP, Razavi MK, Dake MD. Percutaneous balloon fenestration and stenting for lifethreatening ischemic complications in patients with acute aortic dissection. J Thorac Cardiovasc Surg 1999;117:1118-26.

21. Fabre O, Vincentelli A, Willoteux S, Beregi JP, Prat A. Preoperative fenestration for type A acute aortic dissection with mesenteric malperfusion. Ann Thorac Surg 2002;73:950-1.

22. Shrestha M, Fleissner F, Ius F, Koigeldiyev N, Kaufeld T, Beckmann E, Martens A, Haverich A. Total aortic arch replacement with frozen elephant trunk in acute type A aortic dissections: are we pushing the limits too far? Eur J Cardiothorac Surg 2015;47:361-6.

23. Estrera AL, Garami Z, Miller CC, Porat EE, Achouh PE, Dhareshwar J, Meada R, Azizzadeh A, Safi HJ. Acute type A aortic dissection complicated by stroke: can immediate repair be performed safely? $J$ Thorac Cardiovasc Surg 2006;132:1404-8.

24. Wong DR, Coselli JS, Palmero L, Bozinovski J, Carter SA, Murariu D, LeMaire SA. Axillary artery cannulation in surgery for acute or subacute ascending aortic dissections. Ann Thorac Surg 2010;90:731-7.

25. Tiwari KK, Murzi M, Bevilacqua S, Glauber M. Which cannulation (ascending aortic cannulation or peripheral arterial cannulation) is better for acute type A aortic dissection surgery? Interact Cardiovasc Thorac Surg 2010;10:797-802. 